\title{
Comments on Boghossian
}

\author{
John Broome
}

\section{Philosophical Studies}

An International Journal for Philosophy in the Analytic Tradition

ISSN 0031-8116

Philos Stud

DOI 10.1007/s11098-012-9894-7

\section{PHILOSOPHICAL STUDIES}

AN INTERNATIONAL JOURNAL FOR PHILOSOPHY

IN THE ANALYTIC TRADITION

\section{包 Springer}

Springer 
Your article is protected by copyright and all rights are held exclusively by Springer Science+Business Media B.V.. This e-offprint is for personal use only and shall not be selfarchived in electronic repositories. If you wish to self-archive your work, please use the accepted author's version for posting to your own website or your institution's repository. You may further deposit the accepted author's version on a funder's repository at a funder's request, provided it is not made publicly available until 12 months after publication. 


\title{
Comments on Boghossian
}

\author{
John Broome
}

(C) Springer Science+Business Media B.V. 2012

You believe that it rained last night, and you believe that, if it rained last night, the streets are wet. By reasoning you come to believe that the streets are wet. What exactly does your reasoning process consist in?

One thing that happens in the course of it is that your two premise-beliefs cause your conclusion-belief. But there is more to reasoning than that. Not every causal process through which two of your beliefs cause a third is reasoning. Boghossian aims to say what more there is to reasoning than 'mere' causation as I shall call it. He runs through various accounts of reasoning that are supposed to specify the difference.

That it distinguishes reasoning from mere causation is one thing we want from an account of reasoning. We may have other desiderata too. One that comes high on Boghossian's list and mine is that the account should explain how reasoning can be active-something we do, rather than something that happens to us.

Boghossian also specifies that the account should satisfy what he calls the 'taking condition': that in reasoning you come to believe the conclusion because you take it to be supported by the premises. But I think he should not have specified this as a desideratum at the start. We should wait to see whether the account of reasoning we come up with has this consequence. It turns out that the taking condition is indeed satisfied by theoretical reasoning as I account for it. I shall explain why. But an account of reasoning should apply to reasoning of all sorts, and it is not easy to see how the taking condition can be generalized to other sorts besides theoretical reasoning.

For instance, in instrumental reasoning you derive an intention to take a means from an intention to achieve an end. What corresponds to the taking condition there? The taking condition says that you take the contents of your premise-beliefs (which is to say your premises) to support the content of your conclusion-belief (which is to

\footnotetext{
J. Broome $(\varangle)$

University of Oxford, Oxford, UK

e-mail: john.broome@philosophy.ox.ac.uk
} 
say your conclusion). So a corresponding condition would be that you take the content of your premise-intention, which is the proposition that you achieve the end, to support the content of your conclusion-intention, which is the proposition that you take the means. But what makes what you do reasoning is plainly not your taking there to be a support relation between these propositions. More plausibly, you may take the premise-intention itself - the attitude rather than its content- to support the conclusion-intention itself. But that is not parallel to the taking condition.

So let us leave the taking condition aside, and see where an account of reasoning will lead us. Boghossian starts by rejecting several accounts. The one he does not reject is one in which reasoning consists in following a rule of inference. Boghossian has favoured a rule-following account in the past, and he continues to favour it. However, he does now seem to have acquired some anxiety about it, because he cannot find an analysis of following a rule that he deems satisfactory.

It pleases me very much that Boghossian favours a rule-following account of reasoning, and that he continues to stick to it. I favour a rule-following account too, and it boosts my confidence to have him as an ally. In return, I shall try to alleviate his anxiety by offering an analysis of following a rule. My analysis takes a form that he himself dismisses very quickly: that to follow a rule is to act in accordance with a particular disposition of yours. But the disposition I have in mind is more complex than the sort Boghossian considers, so I hope that this analysis may prove satisfactory despite his objections.

\section{A dispositional analysis}

Boghossian's main objection to the dispositional analysis of following a rule is that it makes no difference between reasoning and mere causation. He says: 'This will just look like regular causation of some thoughts by others'. This remark shows he is thinking of a disposition of a particular sort, because it is not true in general that, if one of your beliefs is caused by others as a result of a disposition of yours, that makes the process look like mere causation.

It depends how the disposition works. Many dispositions work through mental activity. Generally when you follow a rule, you do so because you are disposed to follow the rule, and often thinking is involved in your disposition. Take the disposition to answer ' 125 ' to the question of ' $68+57$ ?'. Most of us have that disposition, but most of us will not give the answer without doing some calculation. Our disposition works through calculation, which is an activity of ours. This calculation distinguishes the working of this disposition from mere causation.

Boghossian is not thinking of dispositions like that, which work through reasoning or calculation. He aims to explain reasoning in terms of rule-following. He will not succeed if all the rule-following involved in the explanation is in turn explained by a disposition that itself involves reasoning. When you do some reasoning, the process may break down into some sub-processes that themselves involve reasoning. For instance, when you reason by modus ponens, you may do some reasoning in identifying what is the antecedent and what is the consequent of 
the conditional proposition you are reasoning with. That will require some lowerlevel rule-following. But if rule-following is to explain what reasoning is, eventually you must do some rule-following that does not involve reasoning. Moreover, as Boghossian shows clearly, it must not depend on a belief (or any intentional attitude) whose content is that you should act this way. As Boghossian earlier put it, following Wittgenstein, this sort of rule-following must be done 'blindly'(Boghossian 2008).

If blind rule-following is acting in accordance with a disposition, that disposition cannot work out by reasoning. Let's call it a 'blind disposition'. I think Boghossian's worry is that the working of a blind disposition will be mere causation. But if we pay attention to the way that even a blind disposition to follow a rule works, we will see it amounts to more than mere causation.

Boghossian claims support from Kripke's objection to the dispositional theory of rule-following (Kripke et al. 1982). One of Kripke's objections is that a disposition could not justify you in acting in the way you are disposed to act. Kripke deploys the argument of Wittgenstein's that, if the disposition justified you, there would be no difference between your action's seeming right and its being right. 'Whatever is going to seem right to me is right. And that only means that here we can't talk about "right", says Wittgenstein (1968).

To appreciate the point, we must distinguish two sorts of rightness. Let weak rightness be correctly following a rule, and let strong rightness be correctly following a correct rule. Kripke's mention of justification is slightly misleading in this context. The notion of justification most naturally goes with strong rightness, but strong rightness is not at issue. Boghossian's question is what distinguishes reasoning from mere causation. The correctness of reasoning is irrelevant to that. Incorrect reasoning differs from mere causation just as correct reasoning does. Incorrect reasoning is not justified in the usual sense, but it is still reasoning.

So let us take 'right' to mean weakly right, and Wittgenstein's complaint to be that whatever is going to seem weakly right to you is weakly right. Even if that were true, it would not follow that acting according to a mere disposition is automatically right, because it may not seem right. Suppose you are asked to pick a number at random, and supposed you are disposed by your psychological state to pick 125. If you act according to this disposition, your choice of 125 will not seem right to you-at least not in the way in which it would seem right if you were answering the question '67 + 58?'.

However, Kripke at this point in his argument takes it for granted that, if you act in accordance with a disposition, your action will seem right to you. This tells us that the sort of disposition he is thinking of is not a disposition just to act in a particular way. It is a disposition to act in a particular way and for that way of acting to seem right to you.

I believe that acting in accordance with a disposition of this more complex sort constitutes following a rule. The disposition encodes the rule, though not in the simplest way, as will appear. It is seeming right that distinguishes following a rule from mere causation. In particular, it distinguishes reasoning from mere causation. 


\section{Seeming right and being right}

When an act seems right to you, it does so in relation to a particular rule. The same act may seem right relative to one rule but not right relative to another. When you are asked to pick a number at random and you pick 125, your act will seem right relative to the rule of picking a number at random when asked to do so, but not relative to any arithmetical rule. When you infer $r \vee \neg r$ from $p$ and $p \rightarrow q$, this will seem right relative to the rule of inferring a tautology but not relative to the modus ponens rule. When you infer $q$ from $p$ and $p \rightarrow q$, this will seem right relative to the modus ponens rule, but not relative to the rule of inferring a tautology.

This means you must have a way of identifying different rules to yourself, which means identifying different dispositions. You must be able to identify some disposition as the modus ponens one, for instance. You can even choose which rule to follow. If you choose the modus ponens rule, this explains why you infer $q$, rather than something else, from $p$ and $p \rightarrow q$.

Choosing a rules mean choosing a disposition. This is not as mysterious as it may sound, and it does not imply you can map out in advance where the disposition will lead in all cases. When you choose whether to walk or run, you choose between a disposition to move your limbs in one way and a disposition to move them in another. You could not map out in advance just what movements these dispositions would lead to, for instance as you cross rough ground.

An act's seeming right to you is an attitude of yours that has a double content consisting of the act and a particular rule. The act seems right relative to the rule. The attitude either consists in, or is manifested by, a complex disposition. It is not a feeling or a phenomenal state, though it may be associated with one. It may also be associated with the absence of any particular phenomenal state. Compare seeming normal. When a journey seems normal to you, that seeming may be associated with the absence of any particular phenomenal state.

An essential part of the attitude of seeming right is recognizing the possibility of correction. You recognize that a certain sort of challenge to your act is appropriate and may succeed. We may call the challenge 'checking'. When an act seems right to you, relative to a particular rule, you recognize that it might no longer seem right to you if you were later to check what you did.

This recognition appears as a disposition. Having the attitude of seeming right involves a disposition to stop having this attitude in particular circumstances, specifically if you were to check the act and it were no longer to seem right. This is a counterfactual disposition, since you might never check. You may not be disposed to check—-perhaps because you are confident—but you still have this counterfactual disposition.

Checking may consist simply in trying again in the same way to follow the rule, or it may involve something more. Since you have learnt your tables, if you are asked '9 6s?', you may spontaneously answer '54', following the rule of multiplication. You may later check by calling up again your spontaneous response, or alternatively by subtracting 6 from 60 . The latter sort of checking will involve following lower-level rules. 
When you act without following a rule-for instance when you pick a number at random - the attitude you have to your act is nothing like this. There can be no such thing as checking your choice.

Because seeming right recognizes the possibility of correction, Wittgenstein is wrong to say that whatever is going to seem right is right. An act might seem right without being right: there is a distinction to be made between seeming right and being right. I have not yet made this distinction, because I have not said what being right consists in. For my purposes that does not matter; it matters only that being right can be distinguished from seeming right.

Still, I am willing to venture cautiously a definition of being right. Remember I am defining only weakly right, so that correctly following an incorrect rule counts as right. I suggest that, for an act to be weakly right relative to a rule is for you to have a settled disposition for it to seem right relative to the rule. By this I mean that, were you to check several times, the act would generally seem right relative to the rule. The rule is encoded in your settled dispositions, rather than in your simple dispositions for particular acts to seem right.

Nevertheless, I have defined following a rule to consist in acting in accordance with a simple disposition to act in a particular way and for your act to seem right relative to the rule. Since the act may seem right without being right, on this definition mistakenly following a rule counts as following a rule, so long as your mistake seems right to you. It is an arbitrary choice of mine to use 'following a rule' this way, and for some purposes another definition might be preferable. But for my purposes this is the right choice. Reasoning mistakenly is reasoning. So if reasoning is to be following a rule, mistakenly following a rule must be following a rule.

We now have the materials to explain two ways of going wrong in reasoning. One is following a rule incorrectly; in this case you are neither weakly nor strongly right. The other is following an incorrect rule. In this case you are strongly wrong but you may be weakly right.

\section{Reasoning as something you do}

I think this account of reasoning in terms of rule following satisfactorily separates it from mere causation, and makes it something you do. You have the attitude of seeming right towards your act, and this gives it a personal endorsement. True, it is subpersonal causal process that determine what seems right to you. But subpersonal causal processes underlie everything we do; we cannot be in personal control of every part of every act. When you sign a letter, subpersonal causal processes determine that your fingers move in just the way that forms your signature.

In the case of theoretical reasoning, there is something to add. When you reason theoretically following a rule, you are not merely following the rule idly. You end up believing the conclusion that the rule takes you to. This is to give the rule a particularly strong sort of endorsement. You would not believe the conclusion if you did not take the premises to imply the conclusion, or at least to support it. You may not consciously believe that the premises support the conclusion. Even so, we may treat your disposition to believe the conclusion when you believe the premises, and 
for this to seem right, as itself implicitly taking the premises to support the conclusion. Since you believe the conclusion because of your disposition, you believe it because you take the premises to support the conclusion. So you satisfy Boghossian's taking condition.

\section{Reasoning and normativity}

Here is Boghossian's statement of the taking condition:

Inferring necessarily involves the thinker taking his premises to support his conclusion and drawing his conclusion because of that fact.

That the premises support the conclusion is not a normative proposition. So the taking condition does not imply that a reasoner has any normative thought. But in other places Boghossian suggests that the thinker must take the premises to be reasons for believing the conclusion. This is to impute a normative thought to the reasoner. I want to finish by opposing the common idea that normative thoughts are necessary for reasoning.

First I need to clarify the meaning of the word 'normative'. Any rule sets up a standard of correctness: conforming to the rule is correct according to this standard. In a weak sense, 'normative' just means pertaining to a standard of correctness. In this sense, any rule is normative. I have been using 'right' in a corresponding weak sense. In that sense it is a synonym for 'correct'. So it is a normative term in this weak sense.

I do not use 'normative' in that sense. I use it to mean pertaining to reasons or ought. I believe this is the standard meaning among philosophers of normativity. Although a rule is inevitably normative in the weak sense, it need not be normative in this strong sense. Just because there is a rule, that does not mean you have any reason to follow it. Nor does it mean you have any reason to do the individual acts that are entailed by following it.

Nor need you even take yourself to have any reason to follow the rule, even if you do follow it. Suppose you walk down the sidewalk playing the childish game of not stepping on the lines. You shorten your pace when you see that otherwise you would step on a line. You follow the rule of not stepping on the lines. If you avoid a line, that will seem right to you. If you step on the line, that will seem wrong. Yet you need not take yourself to have any reason to avoid stepping on the lines. Indeed, you may chide yourself for doing it.

Similarly, when you reach a conclusion by reasoning, following a rule, you need not take yourself to have any reason to believe the conclusion. You need not have that normative thought.

Boghossian says you do need to take yourself to have a reason to believe the conclusion. However, he says early in the paper that by 'reason' he means 'explanatory reason', and I think he means to deny that he gives the word a normative meaning. But unfortunately, in the expression 'take to be a reason' as he uses it, a normative meaning is inevitable. 
'Reason' does indeed have non-normative (in the strong sense of 'normative') senses. For instance, we say that the reason a stick looks shorter in water is that light is refracted at the water's surface. Or suppose Karen drinks a potion because it contains cadmium and she believes cadmium will do her good. We may say that her reason for drinking the potion is that it contains cadmium. We may say so even if we do not believe cadmium does her good, and indeed even if we believe she has no normative reason at all for drinking the potion. So in saying her reason for drinking the potion is that it contains cadmium, we are evidently using 'reason' nonnormatively.

However, when you take something to be a reason for acting, and you act because you do, 'reason' has its normative sense. Karen takes the fact that the potion contains cadmium to be a reason for drinking it, and that is why she drinks it. She must take it to be a normative reason, because otherwise it would not explain her drinking. So when Boghossian says that following a rule involves taking something to be a reason, he is using 'reason' in its normative sense despite himself.

I therefore think his expression 'taking something to be a reason' takes Boghossian further than he would want to go. It implies that normative thoughts are necessary for reasoning. It is also further than he should go. You cannot take something to be a reason unless you know what it is for something to be a reason. Yet that piece of normative knowledge is not required simply for you to be able to follow a rule. In particular, it is not required if you are to be able to do reasoning.

The notion of seeming right is not normative in the strong sense, and it provides a sufficient account of what it is to follow a rule.

Acknowledgments I am extremely grateful to Paul Boghossian for extended discussions about reasoning and about the content of this comment in particular. I am also very grateful to Anandi Hattiangadi and Guy Kahane for exceptionally useful comments.

\section{References}

Boghossian, P. (Ed.) (2008). Blind reasoning. In Content and justification (pp. 266-287). Oxford: Oxford University Press.

Kripke, S. (1982). Wittgenstein on rules and private language. Oxford: Blackwell.

Wittgenstein, L. (1968). Philosophical investigations. Oxford: Blackwell, remark 258. 